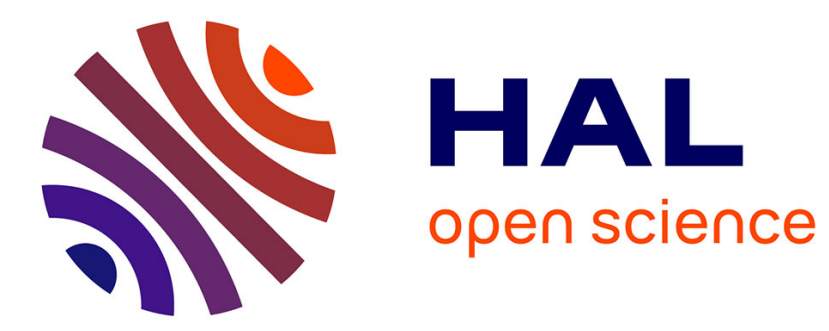

\title{
A NEUTRON INELASTIC SCATTERING STUDY OF PHONONS IN METASTABLE BETA-GALLIUM
}

\author{
J. Copley, Louis Bosio, Robert Cortès, J. Lefebvre, W. Teuchert
}

\section{To cite this version:}

J. Copley, Louis Bosio, Robert Cortès, J. Lefebvre, W. Teuchert. A NEUTRON INELASTIC SCATTERING STUDY OF PHONONS IN METASTABLE BETA-GALLIUM. Journal de Physique Colloques, 1981, 42 (C6), pp.C6-386-C6-388. 10.1051/jphyscol:19816112 . jpa-00221173

\section{HAL Id: jpa-00221173 https://hal.science/jpa-00221173}

Submitted on 1 Jan 1981

HAL is a multi-disciplinary open access archive for the deposit and dissemination of scientific research documents, whether they are published or not. The documents may come from teaching and research institutions in France or abroad, or from public or private research centers.
L'archive ouverte pluridisciplinaire HAL, est destinée au dépôt et à la diffusion de documents scientifiques de niveau recherche, publiés ou non, émanant des établissements d'enseignement et de recherche français ou étrangers, des laboratoires publics ou privés. 
A NEUTRON INELASTIC SCATTERING STUDY OF PHONONS IN METASTABLE BETA-GALLIUM

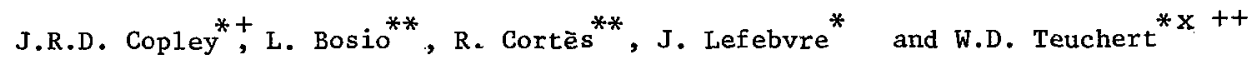

* Institut Lawe-Langevin, $156 \mathrm{X}$ Centre de Tri, 38048 Grenoble Cedex, France

** Groupe de Recherche no. 4 du C.N.R.S., Physique des Liquides et Electrochimie, associé à l'Université Paris VI, 4 Place Jussieu, 75230 Paris Cedex 05, France.

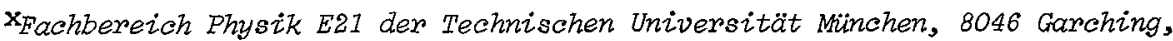
F.R.G.

Abstract. - The phonon dispersion curves of C-centred monoclinic beta-gallium at the melting temperature have been measured along five symetry directions. The behaviour of the lower longitudinally polarised branch in the $\Xi_{X}\left(S_{X}\right)$ direction suggests a desire to double the size of the unit cell. Initial model fitting calculations indicate that the interactions in $\beta-G a$ are of reasonably long range.

1. Experimental Measurements and Results. - The phonon dispersion curves of the stable orthorhombic $\alpha$ form of $\mathrm{Ga}$ were measured some years ago by Reichardt et al [1] and by waeber [2]. In the present paper we discuss measurements and preliminary calculations of phonons in the metastable monoclinic $\beta$ modification of this metal. The experimental details of this work are fully described elsewhere [3]. The main interest in $\beta-G a$ stems from its close structural and thermodynamic similarity to amorphous $\mathrm{Ga}$ and liquid $\mathrm{Ga}$.

Three-axis spectrometer measurements were made using the IN2 and IN8 instruments at the ILL, Grenoble. Crystals were grown and oriented in situ, using a specially constructed goniometer and cryostat. Precautions were also necessary to reduce shock and vibration, in order to avoid accidental transformation to the stable $\alpha$ phase. Measurements were made at the melting temperature, $256.8 \mathrm{~K}$, in the symmetry directions $\Xi_{x}\left(S_{x}\right), \Delta, E_{z}, S_{z}$ and $R$. Unusual features of the measured curves include the similar slopes of the three longitudinal acoustic branches, and the near mirror symmetry about $(0.5,0,0)$ of the lower longitudinally polarised branch in the $\Xi_{x}\left(s_{x}\right)$ direction (fig. 1). This latter feature suggests a desire to double the size of the unit cell by suppression of the C-centred lattice points.

2. Calculations.- The primitive unit cell contains 2 atoms. Its symmetry implies the following relationships between elements of the dynamical matrix $\underset{\approx}{\mathrm{D}}: \mathrm{D}_{\alpha \beta}(\mathrm{q} l 1)=\mathrm{D}_{\beta \alpha}(\underline{q} 22)$, and $\mathrm{D}_{\alpha \beta}(q \mathrm{q} l 2)=\mathrm{D}_{\beta \alpha}(q 12)$. The submatrices $\underset{\sim}{D}(q k \tilde{k})$ are symmetric and therefore real, in the absence

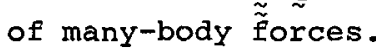

In order to simplify the model fitting calculations we treated

Present address : +Department of Physics, Mc Master University, Hamilton, Ontario, Canada, L8S $4 \mathrm{KI}$

${ }^{++}$Carl Zeiss, Postfach 1369/1380, D-7082, Oberkochen, 


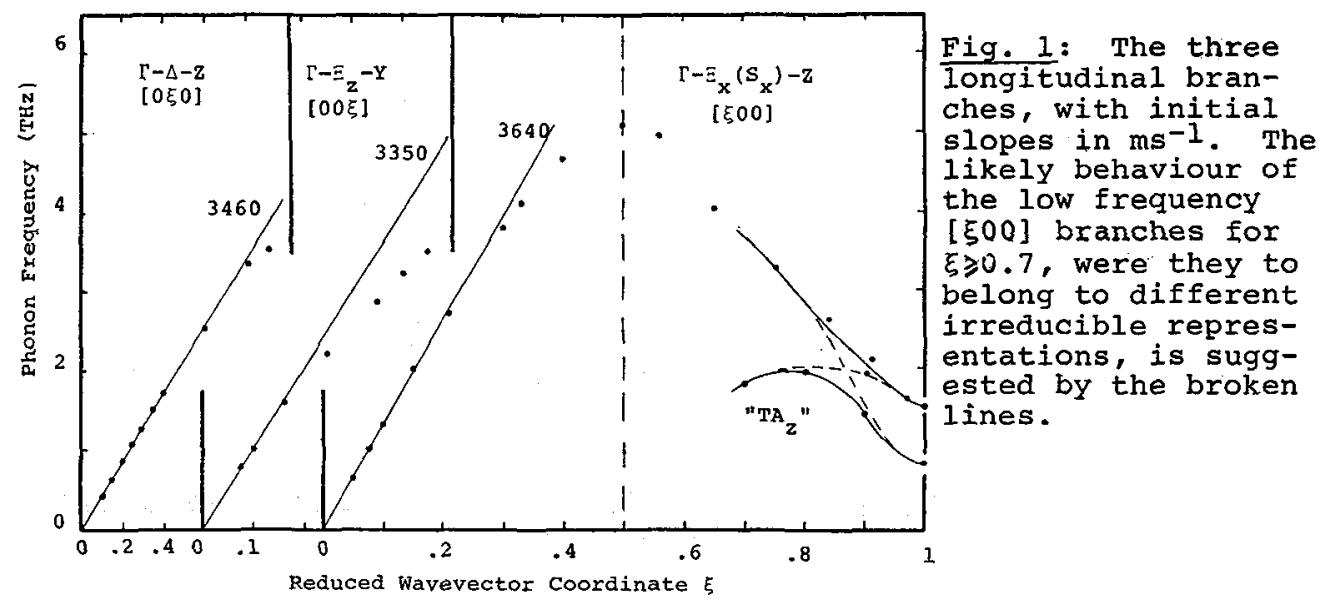

the unit cell as orthorhombic: this is a reasonable approach since $\beta$ is actually $92^{\circ}$, and no new degeneracies are introduced by making it $90^{\circ}$. On the other hand, the number of irreducible representations for a given $g$ is in general increased. Within this approximation, $B-G a$ has the same structure as $\alpha-U$ [4], and the submatrices $\mathrm{Q}$ (qkk) are diagonal (in the absence of many-body forces) for the symmetry directions studied.

Initial attempts to fit the parameters of simple two-body potentials to the experimental results were not surprisingly unsuccessful. Furthermore, dispersion curves computed using real space pair potentials derived from a variety of pseudopotentials calculated for gallium $[5,6,7]$ show little resemblance to experiment.

In the axially-symmetric force model there is a radial force constant $\phi_{r}(i)$ and a tangential force constant $\phi_{t}(i)$ for each shell of neighbours i. Experimental data for the five symmetry directions studied, no matter how precise or detailed they may be, are insufficiently "orthogonal" to determine all the force constants. For $i \leqslant 13$, eight of the force constants linking atoms on the same sublattice may be modified as follows: $\phi_{r, t}(1)+\phi_{r, t}(1)+c, \phi_{r, t}(3)+\phi_{r, t}(3)-c / 2$, $\phi_{r, t}(10) \rightarrow \phi_{r, t}(10)-C, \phi_{r, t}(11) \rightarrow \phi r_{r, t}(11)+C / 2$, and six of the force constants linking atoms on different sublattices may be modified as

follows : $\phi_{r, t}(2) \rightarrow \phi_{r, t}(2)+C^{\prime}, \phi_{r, t}(4) \rightarrow \phi_{r, t}{ }^{(4)+C^{\prime}, \phi_{r, t}}{ }^{(7) \rightarrow \phi_{r, t}}{ }^{(7)-C^{\prime} / 2}$ (where $C$ and $C^{\prime}$ are independent and arbitrary), without in any way modifying $\underset{\approx}{\mathrm{D}}$. It is therefore necessary to impose two arbitrary constraints, e.g. $\phi_{r}(11)=0, \phi_{r}(7)=0$.

Axially-symmetric force constant fits were made allowing interactions out to the 13 th shell of neighbours, over a range of nearly 
6A. With 92 independent data points the "best fit" was relatively poor, having a "goodness of fit" $\chi^{2}$ of $\sim 12$. This is not unexpected in view of the low symmetry of the system: the 13th shell in "orthorhombic" $\beta-G a$ (equivalent to the 19 th shell in true monoclinic B-Ga) is only 2,15 times more distant than the nearest neighbour shell. Also the straightness of the longitudinal acoustic $\Delta$ and $E_{x}$ branches (fig. 1) implies the existence of reasonably long range forces.

3. Discussion.- The low symmetry and long range of interaction in $\beta-G a$ suggest that a reciprocal space analysis of the forces could be fruitful. Alternatively a "modified shell model" analysis, along the lines of Crummett et al's [4] calculations for $\alpha-U$, may be worth pursuing. If at all possible we would like to find a unified description of the forces in $\alpha-\mathrm{Ga}$ and $\beta-\mathrm{Ga}$, in order to shed further light on the nature of the interactions between atoms in the liquid and amorphous states of this unusual but elusive metal.

We are grateful to Mr. Mike Pizzuto for his invaluable help with the model calculations. This work was supported in part by the Natural Sciences and Engineering Research Council Canada. References

[1] Reichardt W., Nicklow R.M., Dolling G. and Smith H.G., Bull. Am. Phys. Soc. 14,378 (1969).

[2] Waeber W.B., J. Phys. C2, 903 (1969).

[3] Bosio L., Cortès R., Copley J.R.D., Teuchert W.D. and Lefebvre J., J. Phys. Fll (1981) (in press).

[4] Crummett W.P., Smith H.G., Nicklow R.M. and Wakabayashi N., Phys. Rev. Bl9, 6028 (1979).

[5] Inglesfield J.E., J. Phys. Cl, 1337 (1968).

[6] Appappillai M. and Williams A.R., J. Phys. F $\underline{3}, 759$ (1973).

[7] Regnaut C., Badiali J.P. and Dupont M., J. de Physique 41, C8603 (1980). 